\title{
Validation of the Job Demands-Resources Model in cross-national samples: Cross- sectional and longitudinal predictions of psychological strain and work engagement
}

\author{
Paula Brough and Carolyn Timms, Griffith University \\ Oi-Ling Siu, Lingnan University \\ Thomas Kalliath, The Australian National University \\ Michael O’Driscoll, University of Waikato \\ Cindy Sit, The University of Hong Kong \\ Danny Lo, Shue Yan University \\ and \\ Chang-qin Lu, Peking University
}

Paula Brough and Carolyn Timms, School of Applied Psychology and Griffith Health Institute, Griffith University, Australia; Oi-Ling Siu, Department of Sociology and Social Policy, Lingnan University, Hong Kong; Thomas Kalliath, Research School of Management, The Australian National University, Australia; Michael O’Driscoll, Department of Psychology, University of Waikato, New Zealand; Cindy Sit, Department of Sports Science and Physical Education, Chinese University of Hong Kong, Hong Kong; Danny Lo, Department of Accounting, Shue Yan University, Hong Kong and Chang-qin Lu, Department of Psychology, Peking University, China.

This research was funded by the Australian Research Council Discovery Project grant scheme (DP0770109).

Correspondence concerning this article should be addressed to: Paula Brough, School of Applied Psychology, Griffith University, Queensland 4122, Australia. Email: p.brough@griffith.edu.au 


\begin{abstract}
The Job Demands-Resources (JD-R) model proposes that employee health and performance are dependent upon direct and interacting perceptions of job demands and job resources. The JD-R model has been tested primarily with small, cross-sectional, European samples. The current research extends scholarly discussions by evaluating the full JD-R model for the prediction of psychological strain and work engagement, within a longitudinal research design with samples of Australian and Chinese employees $(N=9,404)$. Job resources (supervisor support and colleague support) accounted for substantial variance, supporting the motivational hypothesis of the JD-R model. However, minimal evidence was found for the strain hypothesis of the JD-R model. The interactions of job demands and job resources were not evident, with only one from 16 interaction tests demonstrating significance. We discuss explanations for our findings. The implications of testing Western-derived organizational behavior theories among employees employed in Asian regions, especially in regard to the increasing 'westernisation' of many Asian organizations and their employees, are also discussed.
\end{abstract}

Keywords: Job Demands-Resources, psychological strain, work engagement, supervisor support, colleague support. 


\section{Validation of the Job Demands-Resources Model in cross-national samples: Cross-} sectional and longitudinal predictions of psychological strain and work engagement

Explanations for the maintenance of employee health and performance have recently focused on both the negative and positive impact of work experiences, such as how perceived job demands and job resources are directly associated with psychological well-being (e.g., Brough, O’Driscoll, Kalliath, Cooper, \& Poelmans, 2009; Schaufeli, Bakker, \& van Rhenen, 2009; Siu, Lu, Brough, Lu, Bakker, Kalliath, et al., 2010). Theoretical explanations of these negative and positive relationships have been proposed, most noticeably with the Job Demands-Resources (JD-R) model (Demerouti, Bakker, Nachreiner, \& Schaufeli, 2001; Hakanen, Schaufeli, \& Ahola, 2008). In addition, discussions concerning the applicability of Western-derived organizational behavior theories to employees within non-Western countries have also recently increased, due primarily to improved research access to non-Western markets and employees (e.g., Gelfand, Leslie, \& Fehr, 2008; Leung, 2009; Yang, Spector, Sanchez, Allen, Poelmans, \& Cooper, 2012). At the same time, calls for theory-testing with samples residing in regions other than the US and Europe have also occurred, in an attempt to widen the support for key organizational behavior theories (Cadogan, 2010; Gelfand et al., 2008; Tsui, Nifadkar, \& Ou, 2007).

An important omission within the current literature is the test of the complete JD-R model (testing both direct and moderating relationships of the two core processes), using a robust research design (e.g., longitudinal testing), and with both Western and non-Western samples of employees. The current research provides a unique contribution by comparing the effectiveness of the JD-R model to explain psychological strain and work engagement over time, with employees sampled from one Western country (Australia) and one non-Western country (China). The research aims to determine how well the key theoretical tenets of the 
JD-R model are applicable in non-European and non-US samples. The current research, therefore, advances scholarly discussions of employee health and performance by providing the first test of the full JD-R model over time by independent researchers (not the JD-R model's authors) in two large heterogeneous non-European and non-US samples. These methodological and theoretical research strengths answer repeated calls for such comprehensive research designs and for objective theory-testing procedures within this field of organizational behavior (e.g., Brough \& O’Driscoll, 2010; Gelfand et al., 2008).

\section{The Job Demands-Resources (JD-R) Model}

The JD-R model explains occupational stress by two core processes (Bakker \& Demerouti, 2007). The strain process refers to the additional exertion required by an employee to manage (usually negative) job demands whilst maintaining job performance. Persistent exposure to strain is associated with impaired health and performance outcomes such as psychological burnout and work absenteeism. Second, the motivational process is based on the availability of resources (e.g., supervisor support and colleague support) which directly assist an employee to perform their job and to be psychologically engaged with their work (Bakker \& Demerouti, 2007). Job resources are defined as "physical, psychological, social, or organizational aspects of the job that may do any of the following: (a) function in achieving work goals; (b) reduce job demands and the associated physiological and psychological costs; and (c) stimulate personal growth and development" (Demerouti et al., 2001, p. 501). Other theoretical approaches, notably the Job Demands-Control (JD-C) model (Karasek, 1979) and the Job Demands-Control-Support (JDC-S) model (Johnson \& Hall, 1988), also describe how work environments that meet an employee's psychosocial needs for support, autonomy, and feedback are associated with positive outcomes such as individual learning, development, satisfaction, and performance. 
Theoretical convergence has been observed between the JD-R model and other occupational psychosocial theories, most noticeably the JD-C model (Karasek, 1979). However, the authors of the JD-R model argue that distinctions exist. One distinction is the emphasis placed on both the main effects and the interactions between job demands and job resources in the JD-R model. Bakker, van Veldhoven, and Xanthopoulou (2010) argued that, in the JD-R model, job demands are "the most crucial predictors of job strain, while job resources are the most crucial predictors of job motivation, learning, commitment, and engagement" (p. 4). Specifically, high demands and low resources are described as producing the highest levels of psychological burnout and strain, while high demands and high resources lead to high motivation (Bakker et al., 2010). While this description is similar to the strain and motivation hypotheses described in the JD-C (i.e., high demands combined with low control predicts strain, high demands combined with high control predicts motivation; Karasek, 1979), Bakker et al. (2010) specified the distinction to be that "job resources function mainly as moderators in interactions with strain and as predictors in interactions with motivation and learning" (p. 5). The current research specifically tests this dual function of job resources: in respect of psychological strain, job resources will moderate the effects of job demands, whereas in respect of work engagement, job resources are direct predictors (Hypotheses 2 and 3a).

Tests of the JD-R model by its authors have produced positive results. Tests of the direct effects of job demands and job resources have generally supported the two core JD-R model processes, whereby job demands predict health problems (strain process) and job resources predict job involvement (motivational process; Bakker, Demerouti, \& Schaufeli, 2003). Bakker, Demerouti, Taris, Schaufeli, and Schreurs (2003), also demonstrated the main effects of job demands and job resources in the prediction of psychological burnout; such that job demands were positively associated with emotional exhaustion and job resources were 
associated with reduced cynicism and increased professional efficacy. Finally, in another cross-sectional study involving four Dutch samples, Schaufeli and Bakker (2004) also demonstrated significant associations between job demands and psychological burnout, and between job resources and work engagement.

Three cross-sectional investigations by Bakker, Hakanen, Demerouti, and Xanthopoulou (2007), Xanthopoulou, Bakker, Dollard, Demerouti, Schaufeli, Taris, and Schreurs (2007), and Hakanen, Bakker, and Demerouti (2005) tested both the direct effects and the interactional relationships of the JD-R model and also reported support for the model's strain and motivation processes. These studies found that a high proportion of the job demands $\mathrm{x}$ job resources interactions tested were statistically significant. Bakker et al. (2007) noted that 14 of the 18 interactions terms they tested were statistically significant ( $78 \%$ of significant interactions), Xanthopoulou et al. (2007) reported 21 of the 32 interactions terms they tested were significant (66\% of significant interactions), and Hakanen et al. (2005) reported that five of the 10 interactions terms they tested were significant (50\% of significant interactions).

Tests of the JD-R model within a longitudinal research design are scarce but also tend to generally support its theoretical tenets. For example, Boyd, Bakker, Pignata, Winefield, Gillespie, and Stough (2011) demonstrated that job resources (procedural fairness and job autonomy) predicted psychological strain and job commitment over a three year time lag. However, they also reported that job demands were not direct predictors of psychological strain during this period. In another three year study, Hakanen, Perhoniemi, and ToppinenTanner (2008) reported that positive and reciprocal cross-lagged associations were found between job resources and work engagement, thereby supporting the motivational process of the JD-R model. Unfortunately the strain process was not tested by their research. Finally, Schaufeli et al. (2009) reported support for both the strain and motivational processes over a 
one year period. They found increases in job demands and decreases in job resources (including social support) predicted psychological burnout over time, and that job resources predicted work engagement over time. An acknowledged limitation of their research was the small $(N=201)$ homogenous sample of Dutch managers.

Independent tests (by researchers other than the models authors) of the full JD-R model are scarce and are required for theory validation. It is apparent for example, that the interactive relationships of job demands and job resources appear to produce a higher proportion of significant interactions, as compared to the widely acknowledged 'elusive' significant interaction terms of either the JD-C model or the JDC-S model (e.g., Häusser, Mojzisch, Niesel, \& Schulz-Hardt, 2010; Mansell \& Brough, 2005). Calls for the testing of Western-derived theories of organizational behavior to occur with more diverse samples have also recently occurred (e.g., Gelfand et al., 2008; Tsui et al., 2007). Specifically, calls for theory-testing with employees from other regions besides the US or Europe are considered to add meaningful results for theory stability and/or theory adaptation (Cadogan, 2010).

\section{Theory-Testing Beyond the West}

The steady increase of international work assignments and collaborations elicits both practical and academic imperatives for ensuring that theories of organizational behavior tested with Western samples are also applicable to non-Western employees (e.g., Gelfand et al., 2008; Leung, 2009). Spector, Allen, Poelmans, Lapierre, Cooper, O’Driscoll, et al. (2007) suggested that employees in Asian countries may be more sensitive to relational conflict within the workplace, as compared to employees in Western countries, due to a higher value placed on social affiliation by many Asian cultures. This point could have implications for the provision of workplace social support and its perception as a 'job resource' by Asian employees.

Other researchers have reported an increase of 'Western-style' employment concerns 
being experienced by Chinese employers, most noticeably the necessity to retain skilled employees and to encourage employee psychological commitment to the organization (e.g., Clarke, Lee, \& Li, 2004; Sun \& Pan, 2008). It is, therefore, pertinent to ascertain how well current models of organizational behavior developed among Western employees are applicable to non-Western employees, and especially to employees employed within Asian countries where workplace social attitudes appear to be experiencing significant changes.

The theoretical models mentioned above have previously been tested within Asian countries. For example, in a cross-sectional application of the JDC-S model (Johnson \& Hall, 1988) with 867 Japanese employees, Shimazu, Shimazu, and Odahara (2004) reported no significant interactions between job demands and job resources. More recently, in an investigation of the JD-C model testing traditionality, stress and health perceived by Chinese employees, Xie, Schaubroeck, and Lam (2008) found that traditionality significantly moderated the JD-C model interactions. Thus, for employees with high traditionality, the demands x control interactions were statistically significant. Finally,

Finally, in a cross-sectional test of the JD-R model with Chinese employees, $\mathrm{Hu}$, Schaufeli, and Taris (2011) found evidence for the main effects of job demands and job resources on burnout and work engagement, but reported inconclusive evidence for any moderating relationships. None of these investigations provided simultaneous empirical comparisons with Western samples, a methodology which has been specifically recommended for effective cross-national theory testing (e.g., Tsui et al., 2007).

\section{The Current Research}

While some research has evaluated the application of Western-derived organizational behavior theories to employees in non-Western countries (e.g., Cass, Siu, Faragher, \& Cooper, 2003; Lu, Siu, Au, \& Leung, 2009) systematic comparative studies between nonWestern and Western countries, especially from countries outside of the US and Europe, are 
scarce. In consideration of this point, this research, therefore, tested the full JD-R model on employees sampled from both a non-US and non-European Western country (Australia) and a non-Western country (China). Specifically, this research assesses the extent to which job demands and two forms of job resources (supervisor support and colleague support) account for levels of psychological strain and work engagement both cross-sectionally and over time, in samples of Australian and Chinese employees. We present both cross-sectional and longitudinal analyses in order to compare our results with published (mostly cross-sectional) findings and to also test the research hypotheses over time - a point that is still repeatedly requested (e.g., Brough \& O’Driscoll, 2010; de Jonge, van Vegchel, Shimazu, Schaufeli, \& Dormann, 2010). Given that a sound theory is applicable within cross-national contexts and based on the theoretical tenets of the JD-R model, we propose that in both the Australian and Chinese samples, we will identify evidence for the strain process of the JD-R model (H1), the motivational process of the JD-R model (H2), and significant interactions between job demands and job resources (H3). More specifically:

Hypothesis 1: Job demands are primarily and positively associated with psychological strain, as compared to the negative associations between job resources (supervisor support and colleague support) and psychological strain.

Hypothesis 2: Job resources (supervisor support and colleague support) are primarily and positively associated with work engagement, as compared to the associations between job demands and work engagement.

Hypothesis 3: Job resources and job demands will interact such that: Job resources will reduce the positive relationship between job demands and strain (H3a) and job demands will reduce the positive relationship between job resources and work engagement (H3b).

\section{Method}

\section{Participants and Procedure}


The research involved survey data collected twice from employees in Australia and China. Thirteen Australian organizations consisting of finance, health, education, and nongovernment organizations participated with this research, ranging in size from 70 to 4,500 employees. The Chinese participating organizations consisted of a hospital (employing 1,100 employees) and an eyeglasses factory (employing 4,600 employees). Questionnaires were posted in each organization's internal mail system to the research participants and returned via reply-post directly to the researchers at their respective local institutions. Approximately $20 \%$ of questionnaires were also administered on-line. All participants received the same core research instructions. Research ethics approvals from each author's respective Universities were obtained prior to data collection.

Time 1 surveys were administered in 2008 to approximately 10,000 research participants in Australia and to approximately 5,700 research participants in China. Prize draw incentives to encourage survey responses were issued to all the Australian participants. The Chinese respondents each received a small gift (e.g., stationery item) to thank them for their participation. All research participants were also emailed a response reminder within one week of the survey closing date. A total of $N=9,404$ usable Time 1 surveys were returned: Australia $n=5,248$ (52\% overall response rate for the Australian sample) and China $n=4,156$ (73\% overall response rate for the China sample).

Response rates in both countries ranged from $20 \%$ to $73 \%$ for each organization, with an average response rate of $44 \%$. Responses were higher from organizations who posted surveys to named employees; lower responses were received from organizations who distributed an anonymous mass mail-out of the survey. Response rates were also higher from the surveys delivered in hard-copy, compared to the on-line surveys, however some initial technical problems with the electronic survey link accounted for some of the smaller response rate from the on-line respondents. Table 1 describes the demographic characteristics of the 
two groups of respondents.

\section{INSERT TABLE 1 ABOUT HERE}

The questionnaire was administered for a second time (in 2009), after a 12 month time lag, to all the research participants. This 12 month time lag was selected primarily for practical reasons: that is, the participating organisations preferred annual survey administrations. We do also acknowledge the scholarly discussions debating the optimal time lag for multiple survey administrations (e.g., de Jonge, van Vegchel, Shimazu, Schaufeli, \& Dormann, 2010) and that longitudinal tests of the JD-R model have previously been conducted with a 12 month time lag (e.g., Schaufeli et al., 2009). Responses to the second questionnaire were lower compared to the Time 1 responses (Time 2 total $N=3,573 ; 33 \%$ of Time 1 responses). Respondents who could be matched as providing responses to both Time 1 and Time 2 questionnaires consisted of $n=823$ (Australian) and $n=786$ (Chinese; total matched $N=1,609 ; 17 \%$ of Time 1 responses). This matched sample of $N=1,609$ is employed in the longitudinal analyses reported by this paper. Survey matching was based on the self-identified password each participant completed on their surveys. No significant differences in the research variables were noted between those respondents who completed both Time 1 and Time 2 surveys and those respondents who completed Time 1 surveys only.

This research was designed by an international team of researchers. This research, therefore, meets a key recommendation for the conduct of successful cross-national research (i.e., collaborative design by the authors from each country of sample; Milliman \& Von Glinow, 1998). Prior to administration to the Chinese participants, the questionnaire was translated into Chinese and back translated into English to verify semantic equivalence (e.g., Spielberger, Moscoso, \& Brunner, 2005). The translated questionnaire was checked for reliability by test-retest procedures; each research measure produced reliability coefficients in excess of .79. The Chinese (English-speaking) researchers also verified the accuracy of these 
translations and ensured that the meaning of each translated construct was maintained; a common method employed to confirm translation accuracy (e.g., Milliman \& Von Glinow, 1998; Spector et al., 2007).

We undertook two processes to determine the grouping of the Australia and China respondents. First, we noted the results of four independent assessments of samples of employees from these two countries conducted by Gelfand, Bhawuk, Nishii, and Bechtold, (2004), Hofstede, (2001), Oishi, Diener, Lucas, and Suh, (1999), and Spector et al. (2007). These four investigations assessed the similarities and differences of employees from Australia and China (amongst others) and each reported results identifying these samples as two distinctive groups, i.e., Australia (Anglo group) and China (Asian group). These groupings were based on levels of individualism and collectivism reported by their respondents. The second process conducted to test for sample differences involved the testing of each research variable by country. The results of this analysis are reported in the Results section.

\section{Measures}

Job demands. Boyar, Carr, Mosley, and Carson’s (2007) five-item measure of job demands was included. A sample item is "My work demands a lot from me". Respondents indicated their agreement with each item on a five-point scale from 1 (strongly disagree) to 5 (strongly agree). High scores therefore represent high demands. Cronbach's alpha coefficients for job demands within the Australian sample were .88 (Time 1) and .89 (Time 2) and for the Chinese sample were .71 (Time 1) and .79 (Time 2).

Supervisor support and colleague support. A four-item supervisor support subscale and a four-item colleague support subscale (O’Driscoll, Brough, \& Kalliath, 2004) were included. Items were prefaced by the stem "How often did you get the following support from your supervisor/colleague?" and a sample item for both subscales was "Clear and helpful 
feedback". Responses to both subscales were scored on a six-point frequency scale from 1 (never) to 6 (all the time). High scores therefore indicate high support. Cronbach's alpha coefficients for supervisor support for the Australian sample were .94 (Time 1) and .95 (Time 2) and for the Chinese sample were .86 (Time 1) and .88 (Time 2). Cronbach's alpha coefficients for colleague support for the Australian sample were .92 (Time 1) and .94 (Time 2) and for the Chinese sample were .86 (Time 1) and .87 (Time 2).

Psychological strain. The eight-item version (Kalliath, O’Driscoll, \& Brough, 2004) of the GHQ12 (GHQ; Goldberg, 1972) was utilized as a composite measure of psychological strain. Items were prefaced with the stem: "Have you recently experienced the following in the past few weeks..." and an example item was "been feeling unhappy or depressed?" Responses were recorded on a frequency scale from 0 (more so than usual) to 3 (much less than usual), so high scores represent high levels of strain. Cronbach's alpha coefficients for the Australian sample were .87 (Time 1) and .88 (Time 2) and for the Chinese sample were .79 (Time 1) and .80 (Time 2).

Work engagement. The nine-item version of the Utrecht Work Engagement Scale (UWES; Schaufeli \& Bakker, 2003) was included as a composite measure in this research. A sample item was: "I am immersed in my work". The UWES is scored on a seven-point frequency scale from 0 (never) to 6 (always). High scores therefore indicate high engagement. Cronbach's alpha coefficients for the Australian sample were .92 (Time 1) and .91 (Time 2) and for the Chinese sample were .90 (Time 1) and .90 (Time 2).

Finally, demographic questions of gender, marital status, work hours, tenure, and educational qualifications were also included in the surveys. Respondents were also asked to indicate if they currently had responsibilities for dependent children, relatives or any other individuals.

\section{Statistical Analysis}


Marital status was dummy-coded into respondents with a partner/spouse (coded 1) and those without a partner/spouse (coded 0). Dependent responsibility was dummy-coded into respondents with dependent responsibilities (coded 1) and those without dependent responsibilities (coded 0). To test the three research hypotheses both cross-sectionally and longitudinally within the two groups, eight moderated multiple hierarchical regression equations were constructed (that is, four cross-sectional and four longitudinal equations; H1 to $\mathrm{H} 3)$.

The equations were all constructed by the same method: at step one, gender, marital status, dependent responsibility and work hours were entered as control variables. These variables each produced significant bivariate associations with the dependent variables and have variously been included as control variables in published tests of the JD-R (e.g., Hakanen et al., 2005). The strain process of the JD-R model was tested at step two via the main effects of job demands (H1). The motivational process of the JD-R model was tested at step three via the main effects of resources (supervisor support and colleague support; H2). The significant interactions between job demands and job resources was tested in the final step (interactions were calculated via the multiplication of the respective standardized predictor and moderator variables; $\mathrm{H} 3 \mathrm{a}$ and $\mathrm{H} 3 \mathrm{~b}$ ). The longitudinal regression equations also included the respective Time 1 criterion variable entered at the first step, to control for the influence of Time 1 strain or work engagement on the Time 2 criterion variable (Cohen, Cohen, West, \& Aiken, 2003).

Note to avoid any potential order of entry effect, these eight moderated multiple hierarchical regression equations were also each tested with job resources entered before job demands. That is, job resources were entered at step 2 and job demands were entered at step 3 into each equation. The results showed no difference between the two sets of equations: whether job resources were entered into the equations before or after job demands had no 
significant impact on the regression results.

\section{Results}

\section{Sample Group Analysis}

The two samples were tested for distinctiveness via the assessment of sample differences in mean scores for the research variables (e.g., Milliman \& Von Glinow, 1998). A MANOVA (General Linear Model) was conducted with country as the independent variable and the ten Time 1 and Time 2 psychological constructs as dependent variables. The MANOVA results are summarized in Table 2. It can be observed that nine of the ten $F$-tests were statistically significant; demonstrating that overall the mean scores for each dependent variable differed significantly across the two groups. Psychological strain at Time 2 produced no statistical difference between the two groups. The Australian respondents reported significantly higher mean scores for job demands, supervisor support, colleague support, and work engagement in comparison with the Chinese respondents, although only the variables of supervisor support, colleague support, and work engagement produced notable effect sizes. The Chinese respondents reported a significantly higher mean score for Time 1 psychological strain, although the effect size was very small.

\section{INSERT TABLE 2 ABOUT HERE}

\section{Correlation Results}

Table 3 summarizes the bivariate correlations for the Time 1 and Time 2 research variables. Test-retest coefficients for the Time 1 and Time 2 variables ranged from $r=.41(p$ $<.001$; psychological strain) to $r=.60$ ( $p<.001$; job demands) for the Australian respondents and $r=.35$ ( $p<.001$; psychological strain) to $r=.58$ ( $p<.001$; work engagement) for the Chinese respondents. The positive associations between job demands and psychological strain within each sample were all significant, but were not consistently stronger than the negative associations between job resources (social support and colleague support) and psychological 
strain, as was hypothesised (H1). Interestingly, the associations between job demands and work engagement were all positive, rather than negative, as was hypothesised $(\mathrm{H} 2)$. The positive associations between job resources and work engagement were all stronger compared to the associations between job demands and work engagement, as was hypothesised (H2).

\section{INSERT TABLE 3 ABOUT HERE}

\section{Cross-Sectional Moderated Hierarchical Multiple Regression Results}

The four cross-sectional moderated hierarchical multiple regression equations are summarized in Table 4. It can be seen that the prediction of psychological strain across the two groups produced similar results and accounted for similar proportions of variance within each sample. Interestingly, marital status (being single) was a significant predictor of strain for both samples. Job demands (step 2) was a significant positive predictor in each sample. However, only in the Chinese equation did job demands account for more variance compared to job resources in the prediction of psychological strain (step 3; H1). In the Australian equation the reverse occurred: job resources accounted for more variance compared with job demands. The strain process of the JD-R model (H1) is thus only supported with the Chinese sample and not with the Australian sample. The entry of the interaction terms at step 4 was a significant addition for the Australian sample only (significant $\Delta R^{2}$ ), with the job demands $\mathrm{x}$ supervisor support interaction term demonstrating significance and offering some support to H3a. The regression equations overall accounted for small amounts of variance in each sample: $9 \%$ of variance in the Australian sample $F(9,1787)=19.02, p<.001$ and $6 \%$ of the variance in the China sample $F(9,1003)=7.46, p<.001$.

In the prediction of work engagement (Table 4), gender and marital status were significant predictors for both samples, while dependents were also a significant predictor for the Australian sample. Work hours were a significant positive predictor in the Australian equation and a negative predictor for the Chinese sample. The entry of job demands was a 
significant positive predictor for both samples and accounted for a small but significant increase in explained variance (step 2). Job resources (step 3) were significant positive predictors of work engagement in both samples, with supervisor support explaining the largest proportions of unique variance in both samples, offering support for the motivational process of the JD-R model (H2). Despite two interaction terms demonstrating significant unique variance (step 4), the $\Delta R^{2}$ statistics for this step were not significant. These results therefore did not support $\mathrm{H} 3 \mathrm{a}$ or $\mathrm{H} 3 \mathrm{~b}$. The regression equations overall explained similar proportions of variance in each sample: $17 \%$ of the variance in the Australia sample $F(9$, $1804)=41.88, p<.001$ and $20 \%$ of the variance in the China sample $F(9,1023)=27.46, p$ $<.001$.

\section{INSERT TABLE 4 ABOUT HERE}

\section{Longitudinal Moderated Hierarchical Multiple Regression Results}

The four longitudinal moderated hierarchical multiple regression equations are summarized in Table 5 and produced noticeably different results compared to the crosssectional analyses (Table 4). As expected, the Time 1 dependent variables accounted for substantial proportions of variance within each Time 2 equation, signifying the enduring aspects of both psychological strain and work engagement over time (step 1). For the prediction of psychological strain, only marital status and dependents were identified as significant predictor variables within the Chinese equation (step 2). No main effects of Time 1 demands or resources occurred in either equation, producing no support for the longitudinal predictions of $\mathrm{H} 1$ and $\mathrm{H} 2$. Despite one interaction term demonstrating significant unique variance (step 5), the $\Delta R^{2}$ statistics for this step were not significant in either sample, offering no support for $\mathrm{H} 3 \mathrm{a}$ or $\mathrm{H} 3 \mathrm{~b}$. The equations overall accounted for $23 \%$ of the variance in the Australian sample $F(10,130)=3.91, p<.001$ and $16 \%$ of the variance in the Chinese sample $F(10,184)=3.53, p<.001$. 
In the prediction of Time 2 work engagement for the Chinese sample, none of the predictor variables (other than T1 engagement) accounted for any significant variance (Table 5), offering no support for the longitudinal predictions of $\mathrm{H} 1$ and H2. For the Australian sample, supervisor support was a significant negative predictor of work engagement over time (step 4). This negative relationship between supervisor support and work engagement over time was unexpected and did not rather replicate our prediction $(\mathrm{H} 2)$. One interaction term demonstrated significant unique variance (step 5) but its accompanying $\Delta R^{2}$ statistic was not significant. The results therefore offered no support for H3a or H3b. The Time 2 work engagement equations overall explained 59\% of the variance in the Australian sample $F(10$, $127)=18.12, p<.001$ and $35 \%$ of the variance in the Chinese sample $F(10,192)=10.52, p$ $<.001$.

\section{INSERT TABLE 5 ABOUT HERE}

\section{Discussion}

This research tested the two core processes of the JD-R model (the strain process and the motivation process) and examined the interactions between job demands and job resources in two large cross-national samples. Analyses were conducted both cross-sectionally and longitudinally, in order to test the hypotheses over-time and to compare our results with those within the (largely cross-sectional) literature. Following the theoretical tenets of the JD-R model (Demerouti et al., 2001) both the strain and motivation processes and the interactions of job demands and job resources were hypothesised to be evident in both sample groups. The research results supported the motivational process of the JD-R model in the cross-sectional analyses (H2), but produced mixed support for the strain process of the JD-R model $(\mathrm{H} 1)$. Minimal evidence was evident for both the strain process and the motivation process within the longitudinal analyses. The interactions of job demands and job resources were not evident, with only one from 16 interaction tests demonstrating significance (6\% of significant 
interactions). No support for $\mathrm{H} 3 \mathrm{a}$ or $\mathrm{H} 3 \mathrm{~b}$ was therefore evident. Interestingly, the results were generally found not to be dependent on the country of the sample.

\section{Validation of the JD-R Model: The Strain Process}

The strain process of the JD-R model posits that the maintenance of job performance in conditions of high demands results in strain. Job demands (rather than job resources) are thus "the most crucial predictors of job strain" (Bakker et al., 2010, p. 4). This strain process (Hypothesis 1) however, was not clearly evident within the current research. In only one of the four equations predicting psychological strain did job demands account for more variance as compared to job resources (within the Chinese cross-sectional multiple regression equation). Importantly, no evidence of any significant effects of job demands on psychological strain over time was found, which contrasts with Schaufeli et al.'s (2009) observations, but replicates Boyd et al.'s (2011) non-significant longitudinal results. Our results, therefore, offer little support for the evidence of the strain process of the JD-R model reported within the literature (e.g., Bakker et al., 2003a; Bakker et al., 2003b; Schaufeli \& Bakker, 2004).

One possible explanation for the non-significant results produced by this research could be the use of a context-free psychological strain criterion variable. It has been previously noted, for example, that job demands tend to be stronger predictors of workspecific outcomes, such as job satisfaction or work-related well-being, as opposed to contextfree outcomes (e.g., Mansell \& Brough, 2005; Wall, Jackson, Mullarkey, \& Parker, 1996). However, we also note that support for the strain process of the JD-R model using a contextfree measure of psychological burnout has been demonstrated over time (Schaufeli et al., 2009). We discuss further explanations for these findings below.

\section{Validation of the JD-R Model: The Motivational Process}

The motivational process of the JD-R model occurs when job resources are available 
to assist an employee to perform their job and are predictive of levels of work engagement (Bakker \& Demerouti, 2007). Thus: “job resources are the most crucial predictors of work motivation, learning, commitment, and engagement" (Bakker et al., 2010, p. 4). The current research found evidence of this motivational process within three of the four regression equations predicting work engagement $(\mathrm{H} 2)$. Evidence for the motivational process of the JD$\mathrm{R}$ model occurred in the cross-sectional analyses where the contribution of job resources accounted for significantly more (shared) variance as compared to job demands, in the prediction of work engagement for both samples. However, while the proportion of unique variance described by supervisor support was greater than the unique variance of job demands in the prediction of work engagement for both samples, the variance explained by colleague support was comparable to the variance explained by job demands. Therefore, the type of job resources appears to be a crucial element of this motivational process.

The ability of the motivational process of the JD-R model to occur over time, was thus only partially supported by the current research. The current research, therefore, offers only minimal support to other longitudinal observations of the motivational process of the JD-R model (e.g., Boyd et al., 2011; Hakanen et al., 2008b). We discuss further explanations for these findings below.

\section{Validation of the JD-R Model: Interactions of Job Demands and Job Resources}

This research found that only one of the eight job demands and job resources interactions tested within the cross-sectional analyses were statistically significant (13\% of significant interactions), while none of the eight interaction terms tested within the longitudinal analyses were significant ( $0 \%$ of significant interactions). Overall, this research produced one significant interaction term from a total of 16 tests $(6 \%$ of significant interactions). The current research, therefore, produced minimal support for the hypothesised interactions of job demands and job resources and was unable to support Hypotheses 3a and 
3b. Our results are, therefore, markedly different from the proportions of significant job demands $\mathrm{x}$ job resources interaction terms reported elsewhere: for example, $50 \%$ of significant interactions (Hakanen et al., 2005), 66\% of significant interactions (Xanthopoulou et al., 2007), and $78 \%$ of significant interactions (Bakker et al., 2007).

It is important to note that while five interaction terms obtained by this research had non-significant changes in variance $\left(\Delta R^{2}\right)$ they also displayed significant amounts of unique variance assessed by their statistically significant beta weights. Although on the face of it these outcomes appear to conflict, it must be recognised that the significance test is answering different questions in each case. The interaction terms may well predict the criterion (significant beta weight) but may not add to the variance (non-significant $\Delta R^{2}$ ) already accounted for by variables that constitute it. It is the latter question that is central to the issue of whether moderation is involved. The interpretation of interaction terms may also be influenced by sample size. In most cases the inclusion of small sample sizes is acknowledged as a research limitation, and this has implications for the overestimation of any significant interaction terms. Given the large sample sizes of our two cross-sectional analyses $(n=5,248$ and $n=4,156$ ), overestimation of the results is unlikely to be an issue and we are, therefore, able to interpret our moderation results with some degree of confidence.

\section{Theoretical Explanations of the Results}

One explanation for our findings could relate to the specific job demands and job resources variables included in this research. Researchers have suggested that job demands and job resources interactions are unlikely to randomly occur in the prediction of psychological strain. Instead, the likelihood of finding significant interactions is increased if the job demand, job resources and strain variables all address the same domain of human psychological functioning (i.e., cognitive, emotional, or physical domains). This triple match principle (TMP; de Jonge \& Dormann, 2006) extends previous work identifying the relevance 
of testing specific (rather than generic) job demands in the prediction of work-specific outcomes (e.g., work-related well-being, job satisfaction) rather than the prediction of generic psychological strain outcomes (e.g., Mansell \& Brough, 2005; Wall et al., 1996).

However, the TMP suggests that the inclusion of work-specific variables (in our case, job demands, job resources, and work engagement) does not necessarily increase the likelihood of significant job demands x job resources interactions. Ensuring the job demands, job resources, and strain variables each assess the same specific domain of human psychological functioning has, however, been found to increase the proportion of significant interaction results (e.g., Chrisopoulos, Dollard, Winefield, and Dormann, 2010; de Jonge et al., 2010). The testing of the job demands and job resources interactions within the JD-R model, following the principles of the TMP, is therefore recommended as a pertinent enquiry for future research.

A second explanation for our findings is that the theoretical associations between the job demands and job resources variables in the prediction of psychological strain and work engagement may be more transient than has been previously considered. Our cross-sectional results showed consistent associations between job demands, job resources and the two criterion variables, however these results were generally not replicated within the longitudinal analyses. These results imply that simply having sufficient resources at a particular time does not necessarily mean employees will experience reduced strain at a later point (e.g., supervisor support received now may not necessarily influence levels of strain in 12 months time). One implication of this point is that organizations may need to regularly monitor the job resources available to employees to ensure that their on-going needs are met.

From a theoretical perspective, this explanation may indicate that the benefits of job resources are in fact more time-bound and short-lived than has previously been considered. We suggest this point may be especially relevant for cognitive resources and emotional 
resources which may fluctuate more readily (e.g., perceptions of levels of autonomy and social support), compared to physical resources which may demonstrate more stability (e.g., safe physical working environment, clear job task guidelines). Thus de Jonge and Dormann's (2006) triple match principle can be extended to also include the testing of specific samples of workers. For example, factory employees may consider physical job resources to be the most pertinent resources for their health and job performance outcomes, while academics may rate cognitive resources more highly. Thus, the sample of workers is also relevant for the testing of specific job demands, job resources, and strain variables.

We also acknowledge the difficulties repeatedly reported in producing significant interactions of job demands, job control and job support variables over time (for a review see: de Lange, Taris, Kompier, Houtman, \& Bongers, 2003). Similarly, research testing associations between job demands and job resources variables over time rarely includes adequate tests of reciprocal and reverse causation (e.g., Houkes et al., 2003). These two methodological points could explain the mixed results produced by the published longitudinal tests of the JD-R model to date (e.g., Boyd et al., 2011; Schaufeli et al., 2009). This paper contributes to these mixed results by supporting Boyd et al.'s (2011) non-significant findings of the JD-R model's strain process over time. The current research offered no support to Schaufeli et al.'s (2009) observations of significant effects over time for both the strain and motivational process of the JD-R model.

The literature acknowledges that the inclusion of job-specific job demands, in addition to generic job demands, are valuable in the prediction of work-related health and performance outcomes (e.g., Brough, 2004; Brough \& Frame, 2004; Tuckey \& Hayward, 2011). We suggest here that job-specific job resources, in addition to generic job resources, also appear to be valuable in the prediction of work-related health and performance outcomes. The relevance of job-specific job resources was, for example, evident in Hakanen et al.'s (2008a) 
test of the JD-R model in their sample of dentists. We recommend the inclusion of jobspecific job demands and job-specific job resources be further considered by both future research and within theoretical explanations of organizational behavior such as the JD-R model.

\section{Research Limitations}

In comparison with the Australian sample, the Chinese respondents were younger, more likely to be single, had fewer dependents and were not as highly educated. These sample differences can be considered to be advantageous, by the virtue of providing two clearly different heterogeneous respondent groups for the theory-testing undertaken by this research. These demographic sample differences may also, however, confound the research results by reducing the inference of any cross-national differences. Differences in responses in the current results could, for example, also be influenced by generational sample differences (e.g., Dries, Pepermans, \& De Kerpel, 2008). Tsui et al. (2007) provided a pertinent review of cross-national and cross-cultural organizational behavior research and identified some prevalent difficulties, including the presumption that cultural differences account for the most variation across different countries. Cultural values may actually explain less variation in cross-national investigations as compared to other social factors such as national economy, welfare socialism, family strength and educational attainment (Tsui et al., 2007).

The consideration of the extent to which cross-national samples are required to be similar to each other is a highly pertinent point. Some researchers have argued, for example, that differences between sample groups are beneficial in demonstrating the validity of theoretical frameworks across heterogeneous respondents (e.g., Bakker et al., 2010; Milliman \& Von Glinow, 1998; Spector et al., 2007), which was the approach adopted here. Crossnational researchers have also argued that the value of providing cross-national research comparisons exceeds any concerns rising from the use of convenience samples which may not 
be nationally representative (e.g., Straus, 2009).

This research was based on data collected from just two countries, which may be considered a limitation for comprehensive cross-national theory-testing. We acknowledge Cadogan's (2010) observation that international comparative studies should consist of samples from multiple (seven or more) countries in order to fully validate cross-national results. We acknowledge that the research reported in this paper compares the validity of the JD-R model in just two national samples, rather than providing a full cross-national test of the JD-R model. We therefore recommend that future research demonstrates full cross-national theory testing by the inclusion of data collected from multiple (ideally, seven or more) countries.

This paper tested two job resources: supervisor support and colleague support. These are two constructs which have often been included in previous tests of the psychosocial workplace environment (e.g., Brough \& Frame, 2004; Brough \& Pears, 2004; Hakanen \& Roodt, 2010; Karasek, Triantis, \& Chaudhry, 1982). However, we acknowledge the inclusion of these two job resources may be considered to be a limitation and that, therefore, investigations including other multiple sources of job resources is recommended. We do also acknowledge that tests of the JD-R model often include composite job resource variables (e.g., Bakker et al., 2003b); tests of specific job resources are rarer, although the value of including specific job resources has been identified (e.g., Weigl, Hornung, Parker, Petru, Glaser, \& Angerer, 2010).

Finally, this study included constructs assessed by self-report, so we acknowledge that common method bias may also be considered to be a limitation of this research. We also draw attention to the scholarly discussions concerning the actual impact that common methods variance bias may have upon research results (e.g., Conway \& Lance, 2010).

\section{Research Strengths}


This research provides a rare test of the full JD-R model (testing both main effects and interactions) cross-sectionally and over time, in two large heterogeneous non-US and nonEuropean samples. These methodological and theoretical research strengths answer repeated calls for such comprehensive research designs and for objective theory-testing procedures within this field of organizational behavior (e.g., Brough \& O’Driscoll, 2010; Gelfand et al., 2008; Zapf et al., 2006). A key finding of this research was that the results were generally applicable across both sample groups from Australia and China, suggesting the applicability of the JD-R model to these two cross-national populations.

The current research also illustrated the importance of widening the scope of the testing of organizational behavior theories relating to employee health and well-being. Repeated validation of theories in small, cross-sectional, culturally comparable samples is a significant limitation to theory-building. Instead researchers should recognize the value of producing theoretically sound results with broad and diverse samples. Such a methodological recommendation is not new, but has now become a fundamental consideration given the increased ability to theory-test within countries and cultures which were previously largely closed to Western researchers. The increasing assimilation of Western-type working conditions within some non-Western countries (e.g., Clarke et al., 2004; Sun \& Pan, 2008) also reinforces the importance of validating accepted theories of organizational behavior within these non-Western countries, before any applications of these theories actually occur.

\section{Conclusion}

This research compared the applicability of the JD-R model (Demerouti et al., 2001) with two large heterogeneous non-US and non-European samples (Australian and Chinese employees) in the prediction of both psychological strain and work engagement. The main effects of job resources were demonstrated in the cross-sectional analyses, but not in the longitudinal equations, thereby validating the (cross-sectional) motivational process of the 
JD-R model. The strain process of the JD-R model (tested via the main effects of job demands) received limited support. Similarly, minimal evidence was found for the interactions of job resources and job demands in the cross-sectional predictions of work engagement and psychological strain, while no evidence was found that these resources and demands interactions occur over time. The results imply that the theoretical associations between the job demands and job resources variables in the prediction of psychological strain and work engagement may be more transient than has been previously identified. Hence the research offers only partial support for the theoretical JD-R model. Interestingly, the results were generally comparable across the two cross-national samples, signifying no preference for the JD-R model to be supported in either a Western or a non-Western sample. This research also suggested that de Jonge and Dormann's (2006) triple match principle be extended to also include the testing of specific samples of workers. It is also recommended that job-specific job demands and job-specific job resources, in addition to generic assessments of the variables, be considered by future research. Finally, this investigation also answered calls for Western-derived theories of organizational behavior to be tested in other regions besides the US or Europe, a crucial step in theory validation.

\section{References}

Bakker, A. B., and Demerouti, E. (2007). The job demands-resources model: State of the art. Journal of Managerial Psychology, 22, 309-328.

Bakker, A. B., Demerouti, E., and Schaufeli, W.B. (2003a). Dual processes at work in a call centre: An application of the job demands-resources model. European Journal of Work and Organizational Psychology, 12, 393-417. 
Bakker, A. B., Demerouti, E., Taris, T. W., Schaufeli, W.B. and Schreurs, P.J.G. (2003b). A multigroup analysis of the job demands-resources model in four home care organizations. International Journal of Stress Management, 10, 16-38.

Bakker, A. B., Hakanen, J. J., Demerouti, E., and Xanthopoulou, D. (2007). Job resources boost work engagement, particularly when job demands are high. Journal of Educational Psychology, 99, 274-284.

Bakker, A. B., van Veldhoven, M., and Xanthopoulou, D. (2010). Beyond the DemandControl model: Thriving on high job demands and resources. Journal of Personnel Psychology, 9, 3-16.

Boyar, S. L., Carr, J. C., Mosley, J., and Carson, C. M. (2007). The development and validation of scores on perceived work and family demand scales. Educational and Psychological Measurement, 67, 100-116.

Boyd, C. M., Bakker, A. B., Pignata, S., Winefield, A. H., Gillespie, N., \& Stough, C. (2011). A longitudinal test of the job demands-resources model among Australian university academics. Applied Psychology: An International Review, 60, 112-140.

Brough, P. (2004). Comparing the influence of traumatic and organizational stressors upon the psychological health of police, fire and ambulance officers. International Journal of Stress Management, 11, 227-244.

Brough, P., and Frame, R. (2004). Predicting police job satisfaction, work well-being and turnover intentions: The role of social support and police organizational variables. New Zealand Journal of Psychology, 33, 8-16.

Brough, P., and O’Driscoll, M. (2010). Organizational interventions for balancing work and home demands: An overview. Work \& Stress, 24, 280-297.

Brough, P., O’Driscoll, M., Kalliath, T., Cooper, C.L., and Poelmans, S. (2009). Workplace psychological health: Current research and practice. Edward Elgar: Cheltenham, UK. 
Brough, P., \& Pears, J. (2004). Evaluating the influence of the type of social support on job satisfaction and work related psychological well-being. International Journal of Organisational Behaviour, 8(2), 472-485.

Cadogan, J. (2010). Comparative, cross-cultural, and cross-national research. A comment on good and bad practice. International Marketing Review, 27, 601-605.

Cass, M., Siu, O.L., Faragher, B., and Cooper, C.L. (2003). A meta-analysis of the relationship between job satisfaction and employee health in Hong Kong. Stress and Health, 19, 79-95.

Chrisopoulos, S., Dollard, M.F., Winefield, A.H., and Dormann, C. (2010). Increasing the probability of finding an interaction in work stress research: A two-wave longitudinal test of the triple-match principle. Journal of Occupational and Organizational Psychology, 83, 17-37.

Clarke, S., Lee, C. H., and Li, Q. (2004). Collective Consultation and Industrial Relations in China. British Journal of Industrial Relations, 42, 235-254.

Cohen, J., Cohen, P., West, S.G., \& Aiken, L.S. (2003). Applied multiple regression/ correlation analysis for the behavioral sciences. Lawrence Erlbaum Associates, Mahwah, New Jersey.

Conway, J.M., \& Lance, C.E. (2010). What reviewers should expect from authors regarding common method bias in organizational research. Journal of Business Psychology, 25, $325-334$.

de Jonge, J., and Dormann, C. (2006). Stressors, resources, and strain at work: A longitudinal test of the Triple-Match Principle. Journal of Applied Psychology 91, 1359-1374.

de Jonge, J., van Vegchel, N., Shimazu, A., Schaufeli, W., and Dormann, C. (2010). A longitudinal test of the Demand-Control Model using specific job demands and specific job control. International Journal of Behavioral Medicine, 17, 125-133. 
de Lange, A. H., Taris, T., W., Kompier, M. A. J., Houtman, I. L. D., \& Bongers, P. M. (2003). "The very best of the millennium": Longitudinal research and the demandcontrol-(support) model. Journal of Occupational Health Psychology, 8(4), 282-305.

Demerouti, E., Bakker, A. B., Nachreiner, F., and Schaufeli, W. B. (2001). The job demandsresources model of burnout. Journal of Applied Psychology, 86, 499-512.

Dries, N., Pepermans, R., and De Kerpel, E. (2008). Exploring four generations' beliefs about career: Is "satisfied” the new "successful?" Journal of Managerial Psychology, 23, 907-928.

Gelfand, M.J., Bhawuk, D.P.S., Nishii, L.H., and Bechtold, D.J., (2004). Individualism and collectivism. In House, R.J., Hanges, P.J., Javidan, M., Dorfman, P.W., Gupta, V. (Eds.). Culture, leadership and organizations: The GLOBE study of 62 societies (pp. 437-512). Thousand Oaks, CA: Sage.

Gelfand, M., Leslie, L. M., and Fehr, R. (2008). To prosper, organizational psychology should adopt a global perspective. Journal of Organizational Behavior, 29, 493-517.

Goldberg, D. P. (1972). The detection of psychiatric illness by questionnaire. Oxford: Oxford University Press.

Hakanen, J. J., Bakker, A. B., and Demerouti, E. (2005). How dentists cope with their job demands and stay engaged: The moderating role of resources. European Journal of Oral Science, 113, 479-487.

Hakanen, J. J., Perhoniemi, R., and Toppinen-Tanner, S. (2008a). Positive gain spirals at work: From job resources to work engagement, personal initiative and work-unit innovativeness. Journal of Vocational Behavior, 73, 78-91.

Hakanen, J. J., \& Roodt, G. (2010). Using the job demands-resources model to predict engagement: Analysing a conceptual model. In A. B. Bakker \& M. P. Leiter (Eds.), 
Work engagement: A handbook of essential theory and research. (pp. 85-101): Taylor \& Francis.

Hakanen, J. J., Schaufeli, W. B., and Ahola, K. (2008b). The Job Demands-Resources model: A three-year cross-lagged study of burnout, depression, commitment, and work engagement. Work and Stress, 22, 224-241.

Häusser, J. A., Mojzisch, A., Niesel, M., and Schulz-Hardt, S. (2010). Ten years on: A review of recent research on the Job Demand-Control (-Support) model and psychological well-being. Work and Stress, 24, 1-35.

Hofstede, G. (2001). Cultural consequences: comparing values, behaviors, institutions and organizations across nations ( $2^{\text {nd }}$ Ed.) London: Sage Publications, Inc.

Houkes, I., Janssen, P.P.M., de Jonge, J., Bakker, A.B. (2003). Specific determinants of intrinsic work motivation, emotional exhaustion and turnover intention: A multisample longitudinal study. Journal of Occupational and Organisational Psychology 76, 427-450.

Hu, Q., Schaufeli, W.B., and Taris, T.W. (2011). The Job Demands-Resources model: An analysis of additive and joint effects of demands and resources. Journal of Vocational Behavior, 79, 181-190.

Johnson, J., and Hall, E. (1988). Job strain, work place social support and cardiovascular disease: A cross-sectional study of a random sample of the working population. American Journal of Public Health, 78, 1336-1342.

Kalliath, T., O’Driscoll, M., and Brough, P. (2004). Confirmatory factor analysis of the General Health Questionnaire-12. Stress and Health, 20, 11-20.

Karasek, R. (1979). Job demands, job decision latitude, and mental strain: Implications for job redesign. Administrative Science Quarterly, 24, 285-308.

Karasek, R. Triantis, K.P., \& Chaudhry, S.S. (1982). Coworker and supervisor support as 
moderators of associations between task characteristics and mental strain. Journal of Occupational Behaviour, 3, 181-200.

Leung, K. (2009). Never the twin shall meet? Integrating Chinese and Western management research. Management and Organization Review, 5, 121-129.

Lu, C., Siu, O.L., Au, W., and Leung, S. W. (2009). Managers' occupational stress in stateowned and private enterprises in the People's Republic of China. International Journal of Human Resource Management, 20, 1670-1682.

Mansell, A., and Brough, P. (2005). A comprehensive test of the job demands-control interaction: Comparing two measures of job characteristics. Australian Journal of Psychology, 57, 103-114.

Milliman, J. and Von Glinow, M.A. (1998). Research and publishing issues in large scale cross-national studies. Journal of Managerial Psychology, 13, 137-142.

O’Driscoll, M., Brough, P., and Kalliath, T. (2004). Work-family conflict, psychological well-being, satisfaction and social support: A longitudinal study in New Zealand. Equal Opportunities International, 2, 36-56.

Oishi, S., Diener, E.F., Lucas, R.E., and Suh, E.M. (1999). Cross-cultural variations in predictors of life satisfaction: Perspective from needs and values. Personality and Social Psychology Bulletin, 25, 980-990.

Schaufeli, W. B., and Bakker, A. B. (2003). Utrecht Work Engagement Scale: Preliminary Manual. Utrecht: Occupational Health Psychology unit, Utrecht University.

Schaufeli, W. B., and Bakker, A. B. (2004). Job demands, job resources, and their relationship with burnout and engagement: A multi-sample study. Journal of Organizational Behavior, 25, 293-315.

Schaufeli, W. B., Bakker, A. B., and Van Rhenen, W. (2009). How changes in job demands and resources predict burnout, work engagement and sickness absenteeism. Journal of 
Organizational Behavior, 30, 893-917.

Shimazu, A., Shimazu, M., and Odahara, T. (2004). Job control and social support as coping resources in job satisfaction. Psychological Reports, 94, 449-456.

Siu, O.L., Lu, J.F., Brough, P., Lu, C-Q., Bakker, A.B., Kalliath, T., O’Driscoll, M., Chen, W.Q., Lo, D., Sit, C., and Shi, K. (2010). Role resources and work-family enrichment: The role of work engagement. Journal of Vocational Behavior, 77, 470-480.

Spector, P. E., Allen, T. D., Poelmans, S., Lapierre, L. M., Cooper, C. L., O’Driscoll, M., Sanchez, J. I., Abarca, N., Alexandrova, M., Beham, B., Brough, P., Ferreiro, P., Fraile, G., Lu, C-Q., Lu, L., Moreno-Velazques, I., Pagon, M., Pitariu, H., Salamtov, V., Shima, S., Simoni, A. S., Siu, O. L., and Widerszal-Bazyl, M. (2007). Crossnational differences in relationships of work demands, job satisfaction, and turnover intentions with work-family conflict. Personnel Psychology, 60, 805-835.

Spielberger, C. D., Moscoso, M. S., and Brunner, T. M. (2005). The cross-cultural assessment of emotional states and personality traits. In Hambleton, R.K, Spielberger, C. D., and Merenda, P.F. Adapting educational and psychological tests for cross-cultural assessment. (pp. 343-367). Lawrence Erlbaum Publishers: Hillsdale, USA.

Straus, M.A. (2009). The national context effect: An empirical test of the validity of crossnational research using unrepresentative samples. Cross-Cultural Research, 43, 183205.

Sun, L., and Pan, W. (2008). HR Practices Perceptions, Emotional Exhaustion, and Work Outcomes: A Conservation of Resources Theory in the Chinese Context. Human Resource Development Quarterly, 14, 55-73.

Tsui, A. S., Nifadkar, S. S., and Ou, A. Y. (2007). Cross-national, cross-cultural organizational behavior research: Advances, gaps, and recommendations. Journal of Management, 33, 426-478. 
Tuckey, M. R., \& Hayward, R. (2011). Global and occupation-specific emotional resources as buffers against the emotional demands of fire-fighting. Applied Psychology: An International Review, 60, 1-23.

Wall, T. D., Jackson, P. R., Mullarkey, S., and Parker, S. K. (1996). The demands-control model of job strain: A more specific test. Journal of Occupational and Organizational Psychology, 69, 153-166.

Weigl, M., Hornung, S., Parker, S. K., Petru, R., Glaser, J., \& Angerer, P. (2010). Work engagement accumulation of task, social, personal resources: A three-wave structural equation model. Journal of Vocational Behavior, 77, 140-153.

Xanthopoulou, D., Bakker, A. B., Dollard, M.F., Demerouti, E., Schaufeli, W. B., Taris, T.W., and Schreurs, P.J.G. (2007). When do job demands particularly predict burnout? The moderating role of job resources. Journal of Managerial Psychology, 22, 766786.

Xie, J. L., Schaubroeck, J., and Lam, S. S. K. (2008). Theories of job stress and the role of traditional values: A longitudinal study in China. Journal of Applied Psychology, 93, 831-848.

Yang, L.-Q., Spector, P. E., Sanchez, J. I., Allen, T. D., Poelmans, S., Cooper, C.L., Lapierre, L.M., O'Driscoll, M. P., Abarca, N., Alexandrova, M., Antoniou, A.-S., Beham, B., Brough, P., Carikci, I., Ferreiro, P., Fraile, G., Geurts, S., Kinnunen, U., Lu, C.-Q., Lu, L., Moreno-Velazquez, I. F., Pagon, M., Pitariu, H., Salamatov, V., Siu, O-L., Shima, S., Schulmeyer, M. K., Tillemann, K., Widerszal-Bazyl, M., \& Woo,J-M. (2012). Individualism-collectivism as a moderator of the work demands-strains relationship: A cross-level and cross-national examination. Journal of International Business Studies, $43,424-443$.

Zapf, D., Dormann, C., \& Frese, M. (1996). Longitudinal studies in organizational stress 
research: A review of the literature with reference to methodological issues. Journal of Occupational Health Psychology, 1, 145-169. 
Table 1.

Demographic Characteristics for Australia and China Samples

\begin{tabular}{|c|c|c|}
\hline Variable & Australia $(\% ; n)$ & China $(\% ; n)$ \\
\hline \multirow[t]{2}{*}{ Gender } & Female: $67 \%(3,502)$ & Female: $78 \%(3,259)$ \\
\hline & Male: $33 \%(1,733)$ & Male: $20 \%(836)$ \\
\hline \multirow[t]{3}{*}{ Age } & Range: $18-71$ years & Range: $18-62$ years \\
\hline & $M: 41$ years & $M: 25$ years \\
\hline & $S D: 11$ & $S D: 6$ \\
\hline \multirow{2}{*}{ Marital status } & Married: $54 \%(2,807)$ & Married: $35 \%(1,455)$ \\
\hline & Divorced/Single: $46 \%(2,412)$ & Divorced/Single: $63 \%(2,625)$ \\
\hline \multirow[t]{3}{*}{ Tenure } & Range: $0.5-50$ years & Range: $0.5-36$ years \\
\hline & $M: 9$ years & $M: 4$ years \\
\hline & $S D: 9$ & $S D: 5$ \\
\hline Work hours per & Range: 2-90 hours & Range: 5-110 hours \\
\hline \multirow[t]{2}{*}{ week } & M: 40 hours & $M: 46$ hours \\
\hline & $S D: 12$ & $S D: 10$ \\
\hline \multirow[t]{3}{*}{ Dependents } & Range: 0-9 & Range: 0-11 \\
\hline & None: $17 \%(885)$ & None: $6 \%(251)$ \\
\hline & $\geq 1: 20 \%(1,027)$ & $\geq 1: 25 \%(1,033)$ \\
\hline \multirow[t]{2}{*}{ Education } & University degree: $34 \%(1,777)$ & University degree: $33 \%(1,363)$ \\
\hline & Post-graduate: $23 \%(1,192)$ & Post-graduate: $1 \%(51)$ \\
\hline
\end{tabular}

Note. Australia $n=5,248$, China $n=4,156$. 
Table 2.

Mean Score Differences by Country

\section{Australia China}

\begin{tabular}{|c|c|c|c|c|c|c|c|}
\hline Dependent Variables & $M$ & $S D$ & $M$ & $S D$ & $\begin{array}{l}\text { Type III } \\
\text { Sum of } \\
\text { Squares }\end{array}$ & $F$ & $\eta^{2}$ \\
\hline Job Demands (T1) & 18.54 & 4.07 & 17.18 & 2.78 & 601.46 & $46.62 * * *$ & .03 \\
\hline Supervisor Support (T1) & 14.56 & 5.4 & 11.06 & 3.55 & 3949.11 & $175.96 * * *$ & .11 \\
\hline Colleague Support (T1) & 16.43 & 4.55 & 13.07 & 3.66 & 3705.71 & $217.57 * * *$ & .14 \\
\hline Psychological Strain (T1) & 7.69 & 4.04 & 7.76 & 3.70 & 182.08 & $12.15^{* * *}$ & .01 \\
\hline Work Engagement (T1) & 38.22 & 7.93 & 23.83 & 11.00 & 68776.60 & $786.60 * * *$ & .36 \\
\hline Job Demands (T2) & 18.70 & 4.05 & 17.58 & 3.10 & 344.75 & $25.15^{* * *}$ & .02 \\
\hline Supervisor Support (T2) & 11.12 & 4.06 & 8.40 & 2.83 & 2406.61 & $183.84 * * *$ & .12 \\
\hline Colleague Support (T2) & 16.43 & 4.55 & 13.06 & 3.35 & 3839.37 & $226.94 * * *$ & .14 \\
\hline Psychological Strain (T2) & 7.89 & 4.16 & 7.76 & 3.70 & 18.23 & 1.16 & .00 \\
\hline Work Engagement (T2) & 34.70 & 8.0 & 22.34 & 10.70 & 51882.82 & $620.17 * * *$ & .31 \\
\hline
\end{tabular}

Note. $N=9,404$.

$\mathrm{T} 1=$ Time $1, \mathrm{~T} 2=$ Time 2 .

$* * * p<.001$. 
CROSS-NATIONAL JOB DEMANDS-RESOURCES MODEL

Table 3. Correlations and Scale Reliabilities (Australia $n=823$, China $n=786$ )

\begin{tabular}{|c|c|c|c|c|c|c|c|c|c|c|c|c|c|c|c|}
\hline & Variables & 1. & 2. & 3. & 4. & 5. & 6. & 7. & 8. & 9. & 10. & 11. & 12. & 13. & 14. \\
\hline 1. & Gender & & -.04 & $-.17 * *$ & -.04 & -.02 & -.02 & -.02 & $-.10 * *$ & .06 & .04 & .01 & .01 & $-.09 * *$ & $.15^{* * *}$ \\
\hline 2. & Marital & $.11^{* *}$ & & $.33 * * *$ & $-.06^{*}$ & $.14^{* * * *}$ & $.11^{* *}$ & -.07 & $.21 * * *$ & -.05 & $.12 * * *$ & $.12 * * *$ & .00 & $.19 * * *$ & .06 \\
\hline 3. & Dependents & -.05 & $.25^{* *}$ & & .04 & -.07 & -.05 & -.04 & .06 & -.13 & $-.17 * *$ & $-.19 * *$ & -.08 & -.01 & $-.19 * *$ \\
\hline 4. & Work Hours & $-.21 * * *$ & -.02 & -.12 & & .00 & -.03 & .01 & $-.07 *$ & $.09 *$ & -.02 & -.03 & .01 & -.05 & -.03 \\
\hline 5. & Job Demands (T1) & .03 & $.10^{* *}$ & .03 & $.46^{* * *}$ & & $.08 *$ & .02 & $.19 * * *$ & $.08 *$ & $.41 * * *$ & $.08 * *$ & .04 & $.11^{*}$ & $.12 * * *$ \\
\hline 6. & Supervisor Support (T1) & $.15 * * *$ & $.07 *$ & -.01 & $-.16 * * *$ & $-.13 * * *$ & & $.42 * * *$ & $.38 * * *$ & $-.12 * *$ & $.10^{* *}$ & $.42 * * *$ & $.24 * * *$ & $.26 * * *$ & -.03 \\
\hline 7. & Colleague Support (T1) & $.13 * * *$ & $.13^{* *}$ & .01 & -.06 & -.03 & $.45^{* * *}$ & & $.24 * * *$ & $-.08 *$ & -.01 & $.17 * * *$ & $.36 * * *$ & $.12 * * *$ & -.06 \\
\hline 8. & Engagement (T1) & .07 & $-.24 * * *$ & $-.18 *$ & .06 & $.07 *$ & $.24 * * *$ & $.25 * * *$ & & $-.23 * * *$ & $.20 * * *$ & $.26^{* * *}$ & $.17 * * *$ & $.58 * * *$ & -.05 \\
\hline 9. & Strain (T1) & -.05 & $-.12 * * *$ & .13 & $.10^{* *}$ & $.15^{* * *}$ & $-.20 * * *$ & $-.17 * * *$ & $-.27 * * *$ & & .04 & .03 & -.07 & $-.16 * * *$ & $.35 * * *$ \\
\hline 10. & Job Demands (T2) & .00 & .04 & -.01 & $.36 * * *$ & $.60 * * *$ & $-.11 * * *$ & -.01 & .04 & $.10 * *$ & & $.12 * * *$ & .04 & $.21 * * *$ & $.14 * * *$ \\
\hline 11. & Supervisor Support (T2) & $.11 * *$ & $.09 * *$ & .01 & $-.12 * * *$ & $-.12 * * *$ & $.50 * * *$ & $.30 * * *$ & $.17 * * *$ & $-.18 * * *$ & $-.19 * * *$ & & $.24 * * *$ & $.41 * * *$ & .04 \\
\hline 13. & Engagement (T2) & $.15^{* * *}$ & $.14 * * *$ & -.13 & $.08^{*}$ & $.08 *$ & $.21 * * *$ & $.25^{* * *}$ & $.57 * * *$ & $-.28 * * *$ & .06 & $.34 * * *$ & $.30 * * *$ & & $-.10 * *$ \\
\hline 14. & Strain (T2) & -.01 & $-.11 * *$ & $.21^{* *}$ & $.14 * * *$ & $.14 * * *$ & $-.11 * * *$ & $-.17 * * *$ & $-.15^{* * *}$ & $.41 * * *$ & $.21 * * *$ & $-.25 * * *$ & $-.19 * * *$ & $-.40 * * *$ & \\
\hline
\end{tabular}

Note. All tests are two-tailed.

Gender dummy-coded 0 = Male, 1 = Female, Marital status dummy-coded 0 = Single/Separated, 1 = Married/Cohabiting, Dependents dummycoded $0=$ No, $1=$ Yes.

$\mathrm{T} 1=$ Time $1, \mathrm{~T} 2=$ Time 2 .

Australian results presented below the diagonal, Chinese results presented above the diagonal.

$* p<.05, * * p<.01, * * * p<.001$. 
Table 4. Cross-Sectional Moderated Hierarchical Regression for the Prediction of Psychological Strain and Work Engagement by Country

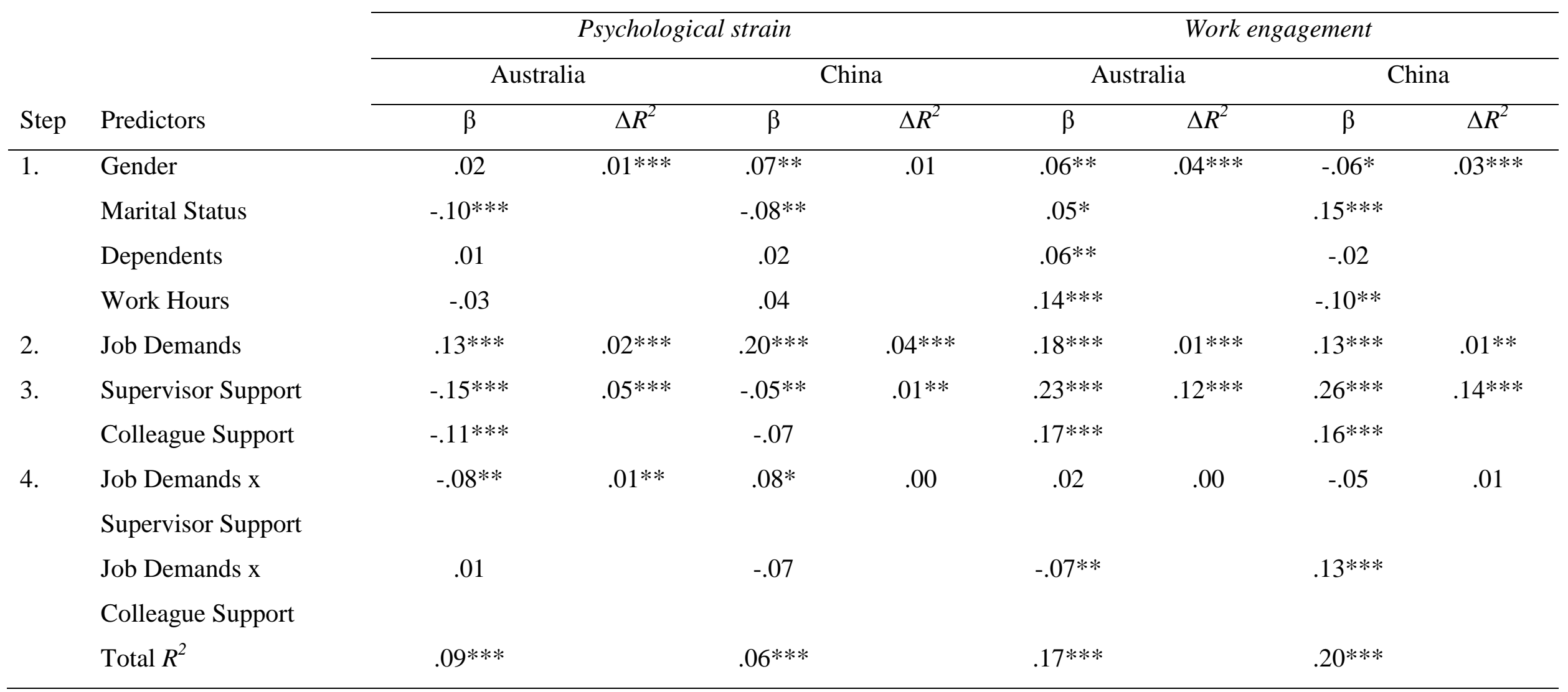

Note. Australia $n=5,248$, China $n=4,156$.

${ }^{*} p<.05,{ }^{* *} p<.01, * * * p<.001$. 
Table 5. Longitudinal Moderated Hierarchical Regression for the Prediction of Psychological Strain and Work Engagement by Country

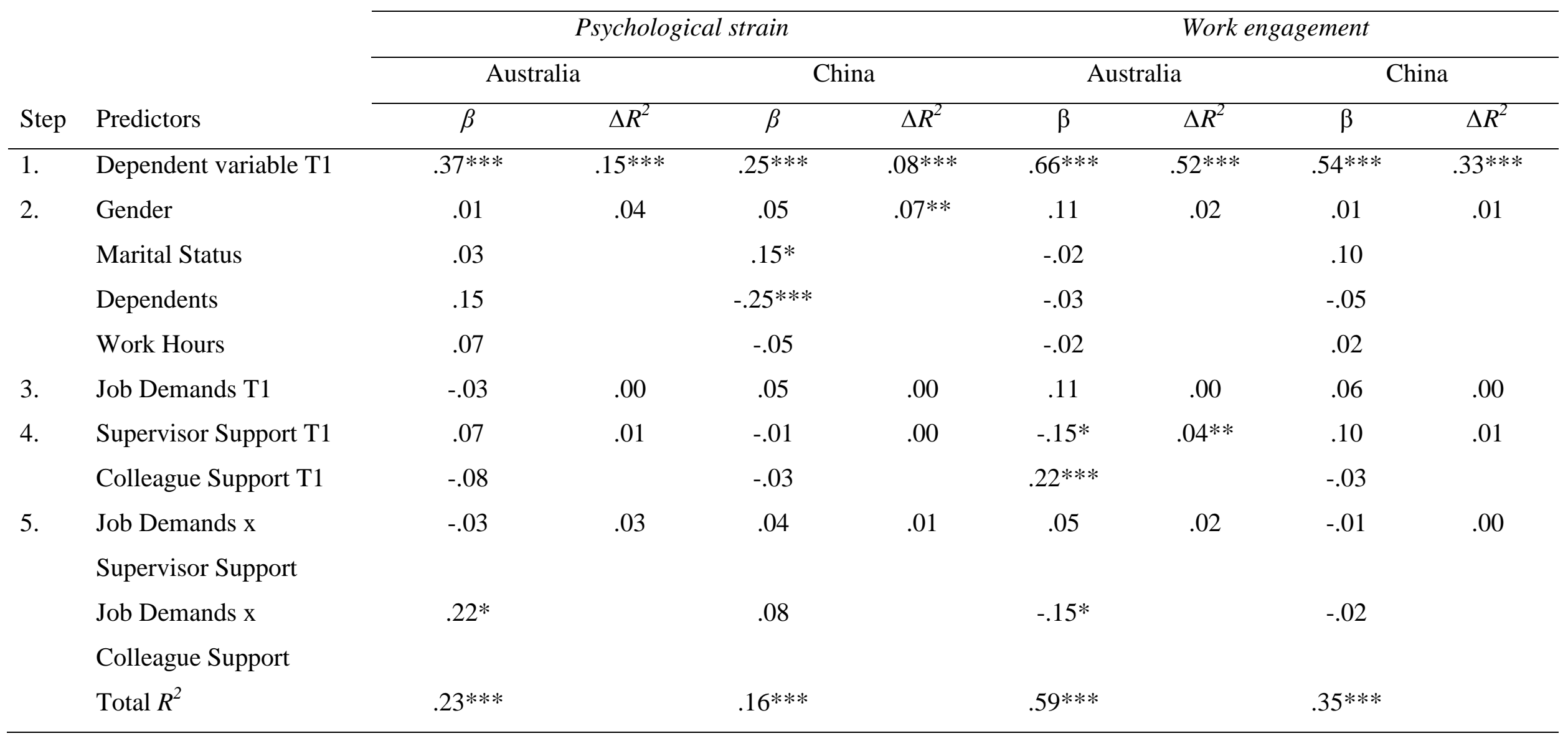

Note. Australia $n=823$, China $n=786$.

$\mathrm{T} 1=$ Time 1 .

$* p<.05, * * p<.01, * * * p<.001$. 